\title{
Development of a Shear Strength Equation for Beam-Column Connections in Reinforced Concrete and Steel Composite Systems
}

\author{
Yun-Chul Choi' ${ }^{1)}$ Ji-Ho Moon'), Eun-Jin Lee ${ }^{3)}$, Keum-Sung Park ${ }^{4)}$, and Kang Seok Lee ${ }^{5), *}$
}

(Received November 29, 2016, Accepted March 23, 2017, Published online May 19, 2017)

\begin{abstract}
In this study, we propose a new equation that evaluates the shear strength of beam-column connections in reinforced concrete and steel beam (RCS) composite materials. This equation encompasses the effect of shear keys, extended face bearing plates (E-FBP), and transverse beams on connection shear strength, as well as the contribution of cover plates. Mobilization coefficients for beam-column connections in the RCS composite system are suggested. The proposed model, validated by statistical analysis, provided the strongest correlation with test results for connections containing both E-FBP and transverse beams. Additionally, our results indicated that Architectural Institute of Japan (AIJ) and Modified AIJ (M-AIJ) equations should be used carefully to evaluate the shear strength for connections that do not have E-FBP or transverse beams.
\end{abstract}

Keywords: connection design, RCS composite system, shear strength equations, statistical analysis.

\section{Introduction}

Buildings are generally designed to have strong columnweak beam systems, where such connections are assumed to have sufficient strength and stiffness to support external loads. However, such connections can be destroyed when unexpectedly strong loads are applied, leading to catastrophic failure of the entire building. For example, forces induced by earthquakes can concentrate on a connection, causing damage that can lead to their failure and the potential collapse of the entire structure.

The load transfer mechanism that occurs at reinforced concrete and steel (RCS) beams is complex. Failure modes at these connections can be categorized as: (1) shear and bearing failure of the internal connection element (Fig. 1a) and (2) bond and shear failure of the external connection element (Fig. 1b). Shear failure is most significant among these failure modes.

\footnotetext{
${ }^{1)}$ Department of Architectural System Engineering, Chungwoon University, Incheon, South Korea.

${ }^{2)}$ Department of Civil Engineering, Kangwon National University, Chuncheon-si, Gangwon-do, South Korea.

${ }^{3)}$ Dongyang Engineering \& Remodeling, Seoul, South Korea.

${ }^{4)}$ Korea Institute of Civil Engineering \& Building Technology, Goyang-si, Gyeonggi-do, South Korea.

${ }^{5)}$ School of Architecture, Chonnam National University, Gwangju 500-757, South Korea.

*Corresponding Author; E-mail: kslnist@jnu.ac.kr Copyright (c) The Author(s) 2017. This article is an open access publication
}

Design equations to estimate the shear connection strength have been proposed by several previous studies (Dierlein 1988; Sheikh and Deierlein 1989; Kanno 1993). The American Society of Civil Engineers (ASCE) Task Committee (1993) suggested a simple modified design equation based on an equation proposed by Deierlein (1988) and Sheikh and Deierlein (1989). Kanno (1993) suggested a shear strength equation for connections based on the ASCE equation that considers the effect of transverse beams and band plates. Several Japanese researchers (Nishimura 1986; Kei et al. 1990, 1991; Mikame 1990, 1992) proposed shear design equations for connections in RCS composite systems; these were subsequently adopted by Japanese Standards (1975 and 1987).

The above studies have resulted in various shear strength equations for connections in RCS composite systems that encompass different variables and thus give inconsistent results. Furthermore, the load transfer mechanism is not fully understood for such connections. Thus, accurate design equations that estimate the shear strength of the connections are still necessary.

In this study, we propose a model that estimates the shear strength of beam-column connections in RCS composite systems. After first analyzing previously proposed shear strength equations including existing researches regarding connections of framing system (Kim and Choi 2006, 2015; LaFave and Kim 2011; Yang et al. 2007; Lim et al. 2016), we developed a shear strength equation for general connections in RCS composite systems, encompassing the effect of extended face bearing plates (E-FBP), transverse beams, and cover plates. Statistical analysis was conducted to verify the proposed equation. This analysis showed that our proposed equation accurately represented the shear strength in RCS composite system connections. 


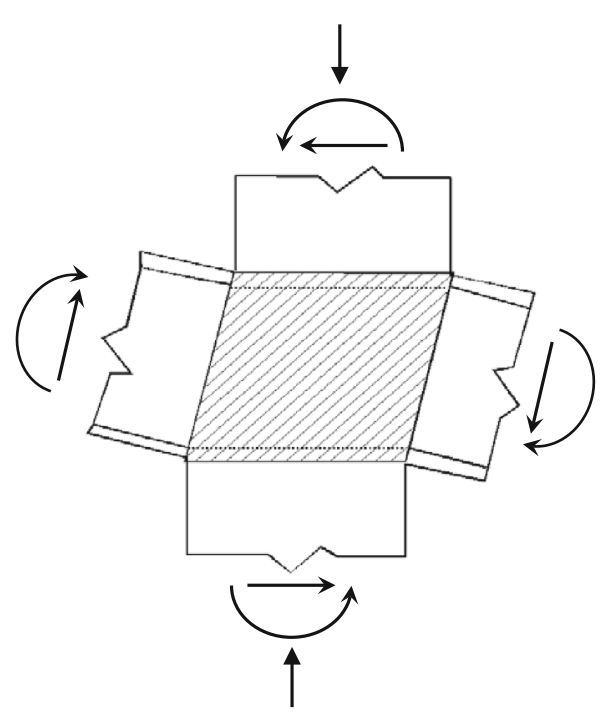

Panel shear failure

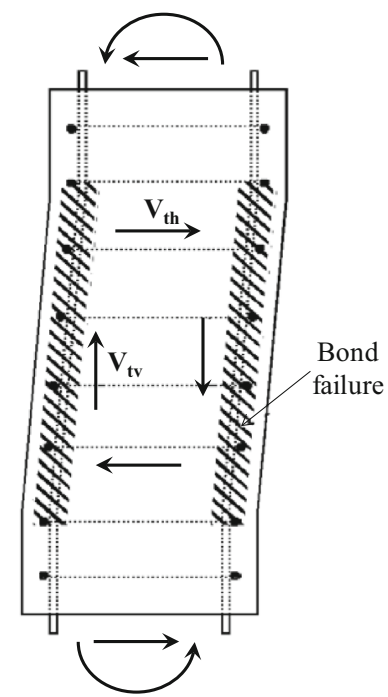

Bond failure

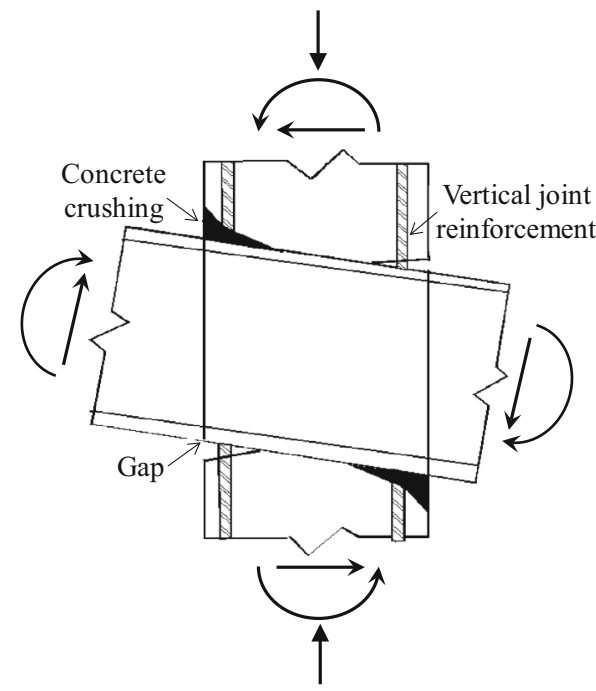

Vertical bending failure

(a)

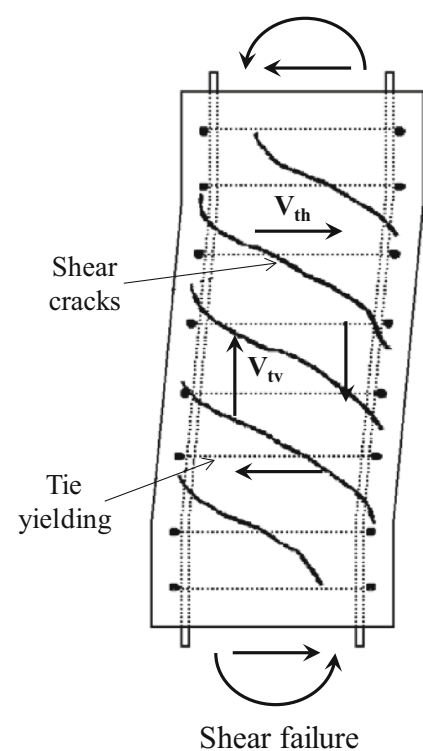

(b)

Fig. 1 Failure modes of connections in reinforced concrete and steel (RCS) composite systems: a internal and $\mathbf{b}$ external element failures.

\section{Background Theory: Evaluating Connection Shear Strength in RCS Composite Systems}

The typical load transfer mechanisms occurring at connections in RCS composite systems are shown in Fig. 2. The connection shear strength can be calculated by summing the contribution of each connection element (including the steel web, as well as inner and external concrete elements), in which the reinforced concrete and steel beam web are the main parts of the connection that resist shearing forces.

The shear strength of reinforced concrete can be obtained by calculating the effective width of internal and external elements; these internal and external elements are divided on the basis of the face bearing plate (FBP). Conventional methods for evaluating the shear strength of concrete can also be used for internal elements, as there are no reinforcements within this material. On the other hand, shear strengths for external elements can be obtained by summing the strength of the concrete and stirrup.

Several studies have previously suggested shear strength equations for connections in RCS composite systems, as shown in Table 1. As observed within this table, each equation takes a different approach to evaluate the connection's shear strength $\left(V_{b}\right)$. The various attributes of equations shown in Table 1 are compared below.

The ASCE design code (1993) adopted the ACI-ASCE 352 equation to evaluate the effective width of external elements $\left(b_{o}\right)$, as shown in Table 1 . This ASCE design code limits the effective width by using one mobilization 


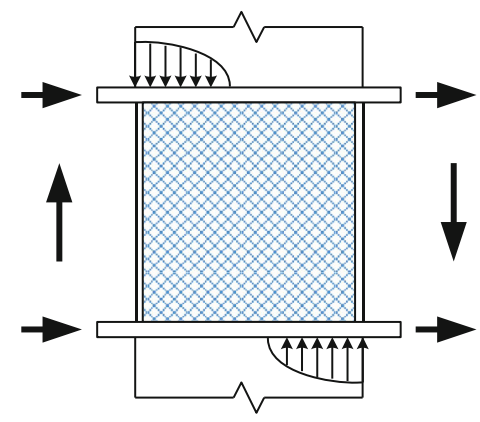

(a)

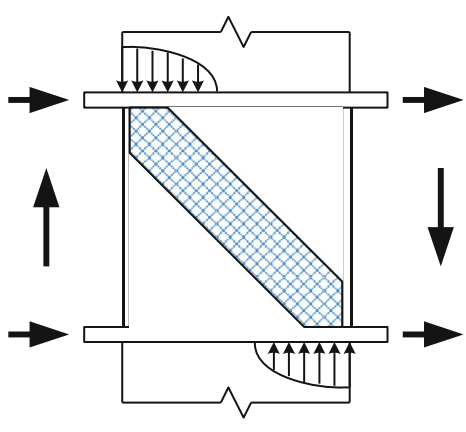

(b)

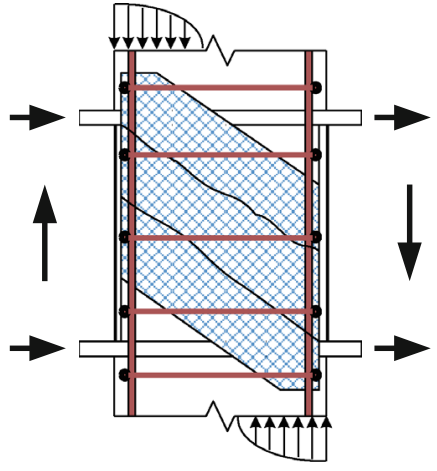

(c)

Fig. 2 Shear resistance mechanism for connections in various RCS composite systems: a steel beam web, b inner concrete strut, and $\mathbf{c}$ compression filled in external concrete element.

Table 1 Shear strength equations for connections in RCS composite systems.

\begin{tabular}{|c|c|c|c|c|}
\hline \multicolumn{2}{|c|}{ ASCE } & & \multicolumn{2}{|c|}{$V_{b}=\frac{\left[V_{s} \cdot d_{f}+0.75 V_{n} \cdot d_{w}+V_{n}^{\prime} \cdot\left(d+d_{o}\right)\right]}{\left[\frac{L_{b}}{L_{c}}\left(L_{c}-d\right)-j h\right]}$} \\
\hline \multicolumn{2}{|c|}{ Kanno } & & \multicolumn{2}{|c|}{$V_{b}=\frac{0.9 d}{L_{b}-h}\left(V_{s}+V_{s f}+V_{n}+V_{n}^{\prime}\right)$} \\
\hline \multicolumn{2}{|c|}{ M-Kanno } & & \multicolumn{2}{|c|}{$V_{b}=\frac{\left(V_{s} \cdot d_{f}+0.75 V_{n} \cdot d_{w}+V_{n}^{\prime} \cdot d\right)}{\left[\frac{L_{c}}{L_{b}}\left(L_{c}-d_{f}\right)\right]}$} \\
\hline Parameters & Symbol & ASCE equation & Kanno equation & M-Kanno equation \\
\hline \multirow[t]{5}{*}{$b_{o}$} & $C$ & $C_{w t}$ & $\max \left(C_{w t}, C_{t}\right)$ & $\max \left(C_{w t}, C_{t}\right)$ \\
\hline & $C_{w t}$ & $(x / h) \cdot\left(y / b_{f}\right) \leq 1$ & $\left(\frac{x}{h}\right) \cdot\left(0.3+0.7 \frac{y}{b_{f}}\right) \leq 1$ & $\left(\frac{x}{h}\right) \cdot\left(0.3+0.7 \frac{y}{b_{f}}\right) \leq 1$ \\
\hline & $C_{t}$ & - & $\frac{1}{2.5}\left(\frac{d}{b-b_{i}}\right)$ & $0.7\left(\frac{x}{h}\right) \cdot\left(0.3+0.7 \frac{y}{b_{f}}\right)$ \\
\hline & $b_{m}$ & $\frac{\left(b_{f}+b\right)}{2}$ & $\frac{\left(\bar{b}_{f}+b\right)}{1.5}$ & $\frac{\left(\bar{b}_{f}+b\right)}{1.5}$ \\
\hline & $\bar{b}_{f}$ & $b_{f}$ & $\begin{array}{c}\max \left(b_{i}, \bar{y}\right) \leq 2 b_{f} \\
\bar{y}=\min \left(y, b_{f}+n \cdot t_{s}\right)\end{array}$ & $\max \left(b_{i}, y\right) \leq 2 b_{f}$ \\
\hline$V_{s}$ & $j h$ & Iteration procedure & $\begin{array}{c}0.8 h \text { (No shear key) } \\
h(E-F B P, \text { Band Plate })\end{array}$ & $0.8 h$ \\
\hline$V_{s f}$ & $V_{s f}$ & - & $4 M_{p f} / d_{f}$ & - \\
\hline$V_{s f}, V_{b}$ & $d_{j}$ & - & $1.25 d$ & $1.1 d$ \\
\hline $\overrightarrow{V_{n}}$ & $\hat{V_{c}}$ & $0.4 \sqrt{f_{c k}} \cdot b_{o} \cdot h$ & $1.05 \sqrt{f_{c k}} \cdot b_{o} \cdot h$ & $1.05 \sqrt{f_{c k}} \cdot b_{o} \cdot h$ \\
\hline
\end{tabular}

$C$ Mobilization coefficient, $C_{w t}$ Mobilization coefficient for shear keys, $C_{t}$ Mobilization coefficient for transverse beam, $\bar{b}_{f}$ Modified beam width, $b_{m}$ Maximum effective connection width, $j h$ Effective steel beam web panel width, $M_{p f}$ Flange plastic moment, $d_{j}$ Effective connection height, $d_{f}$ Flange length, $d_{o}$ Reinforcing element thickness, $L_{b}$ Connection beam length, $L_{c}$ Connection column length, $A S C E$ American Society of Civil Engineers.

coefficient $\left(C_{w t}\right)$, regardless of the existence of transverse beams. However, two different mobilization coefficients, with coefficient factors that consider shear key $\left(C_{w t}\right)$ and transverse beams $\left(C_{t}\right)$, are used in the Kanno equations (Kanno 1993, 2002). Larger values for $C_{w t}$ and $C_{t}$ are also used, which means that only larger effects between the shear key and transverse beam can be captured by this equation. Additionally, the Kanno equations generally result in larger values of $b_{o}$ than the ASCE equation.

Values of $C_{w t}$ represent the effective width of the external element $\left(b_{o}\right)$, including the effect of shear keys. Larger $C_{w t}$ values denote increased strength of the external concrete, due to an increase in the effective width of the concrete. To calculate $C_{w t}$, the length of the stress block ( $x$ and $y$ values in Fig. 3) are first determined. A minimum value of $C_{w t}=0.25$ is used within the ASCE equation when a shear key is not present in the connection. However, in the Kanno equation (1993), values for $x$ are assumed to be 0.7 , and values for $y$ are assumed to be 0 (Fig. 3a); this results in a $C_{w t}$ of 0.21 . When E-FBP is used, $x$ and $y$ are equal to $h$ and $b_{f}$, respectively, as shown in Fig. 3b. In this case, the mobilization coefficient $\left(C_{w t}\right)$ is equal to one, indicating a maximum effective width. 


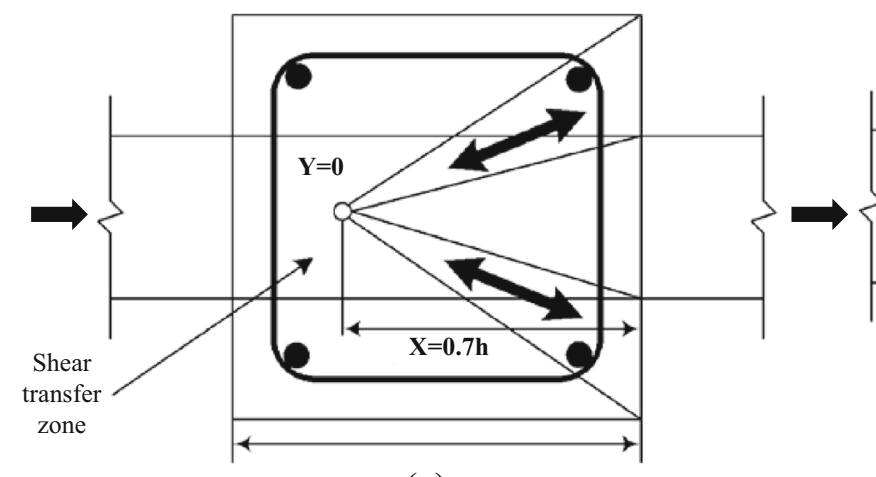

(a)

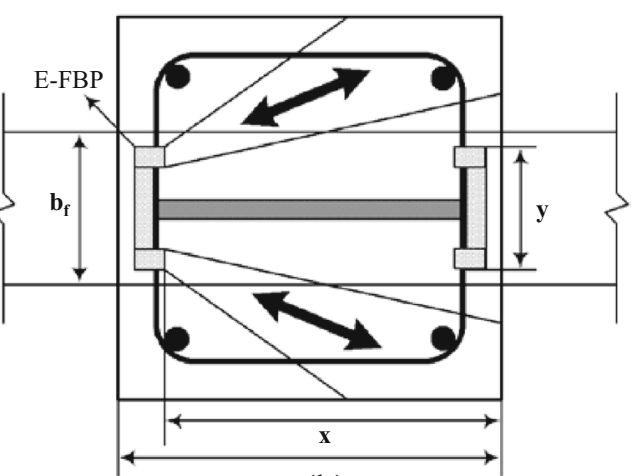

(b)

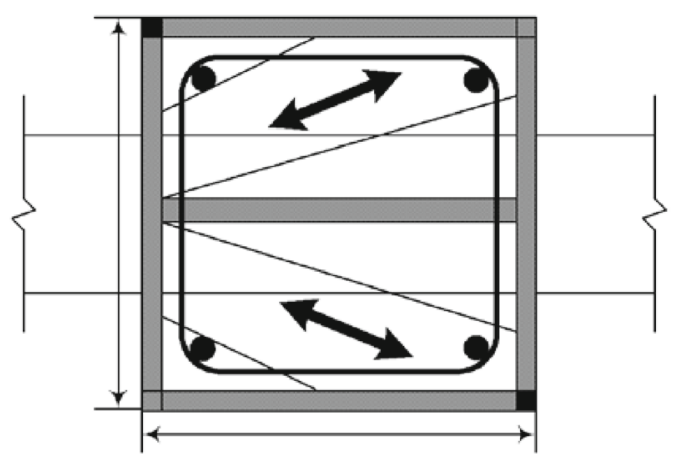

(c)

Fig. 3 Determination of stress block length $x$ and $y$ : a connection without a shear key, b extended face bearing plate (E-FBP) connections, and $\mathbf{c}$ band plate connection.

As shown in Table 1, the ASCE equation does not consider transverse beam effects when calculating $b_{o}$. However, the transverse beam effect is included in Kanno equations for the calculation of $C_{t}$. The mobilization coefficient for transverse beams $\left(C_{t}\right)$ is obtained from the original Kanno equation by considering the transverse beam twist resistance. Values for $C_{t}$ are simply calculated as $0.7 C_{w t}$ in the M-Kanno equation (2002).

The maximum effective connection width $\left(b_{m}\right)$ is assumed to be $1 / 2$ of the total connection and flange width length within the ASCE equation. Both the Kanno and M-Kanno equations use $1 / 1.5$ of the total length, based on a comparison with test results.

In Table 1, values for $j h$ [which is needed to calculate the shear strength of the steel web $\left.\left(V_{s}\right)\right]$ represent the effective steel beam web panel width and are obtained by iteration to find the conversed value within the ASCE equation. In the Kanno equation, $j h$ is defined depending on connection details. For example, when a small column or no shear key is used, $j h$ is equal to $0.8 h$; if E-FBP or band plates are used, $j h$ is assumed to be equal to $h$.

The shear strength of flanges within steel beams $\left(V_{s f}\right)$ is included within the Kanno equation (Table 1). However, this factor is small compared with other variables, and is thus not considered in other equations. To evaluate the concrete strut strength $\left(V_{n}^{\prime}\right)$, the ASCE equation (ACI-ASCE 352) uses a value of 0.4 , while 1.05 is used in Kanno and M-Kanno equations (as shown in Table 1).

\section{A New Equation for Connection Shear Strength in RCS Composite Systems}

As previously discussed, shear strength equations proposed by previous studies differ both in terms of variables included and resulting estimates for strength. Mobilization coefficients, which represent the effects of a shear key and a transverse beam on shear strength, differ considerably among the proposed equations. In this study, we focused on the development of improved mobilization coefficients, while also considering the effects of cover plates on the shear strength equation. The following sections discuss details of how the equation was developed, as well as the proposed equation itself.

\subsection{Effect of Shear Key (E-FBP etc.)}

The shear key (including a E-FBP and band plate) transfers external forces to the inside of the connection, forming a compressive strut inside the connection (Fig. 3) that increases the connection's shear strength within the RCS composite system. The effect of the shear key is included within mobilization coefficients $C_{w t}$ and $C_{w t}$ as a function of the effective width $x$ and $y$ (Fig. 3).

When E-FBP is installed in the connection, the effective width $x$ and $y$ can be determined by considering the compressive strut formed by the shear key (as shown in Fig. 3b). Most of the E-FBP is welded to the flange, where its width is not larger than the flange and $y / b_{f}$ is less than 1 . However, 
when the band plate is used, the width of the shear key (y) can be larger than that of the flange $\left(b_{f}\right)$, as shown in Fig. 3c. In this case, the maximum $y / b_{f}$ value is limited to 1 , as shown in Table 1.

Values of $C_{w t}$ for shear strength equations shown in Table 1 are a function of $y / b_{f}$. However, the compression field varies depending on values of $y$ and the total width of the connection $(b)$, as shown in Fig. $3 b$ and $c$ (Lee et al. 2005). Therefore, the effective width should be determined from $y / b$, rather than $y / b_{f}$. However, when $y / b_{f}$ is used, the shear strength can be overestimated. Test results show that an increase in shear strength upon E-FBP installation is about $15-20 \%$ (Lee 2005). However, strength increases due to E-FBP installation, as calculated by the Kanno equation (which uses $y / b_{f}$ ), are as much as $\sim 50 \%$.

Table 2 shows test specimens used to compare calculated strengths; all test specimens shown in Table 2 have the same dimensions, except for E-FBP (Lee 2005). In Table 2, test specimens JL0-1 and STI-1 do not contain E-FBP; JL0-2 and STI-2 are the same as JL0-1 and STI-1, except for their inclusion of E-FBP. When $y / b$ was used instead of $y / b_{f}$ in strength calculations, the mobilization coefficient decreased from 1 to 0.56 , which matched well with test results. Therefore, it is reasonable to use $y / b$ rather than $y / b_{f}$ to evaluate $C_{w t}$, where the proposed mobilization coefficient is given by changing $b_{f}$ to $b$ :

$$
C_{w t}=\left(\frac{x}{h}\right) \cdot\left(0.3+0.7 \frac{y}{b}\right)
$$

In this equation, $C_{w t}$ is the mobilization coefficient (including the shear key effect), $h$ is the connection length, $y$ is the effective width in the $y$ direction (including the shear key effect), and $b$ is the connection width.

\subsection{Transverse Beam Effect}

The addition of a transverse beam increases the connection's shear strength; for example, Kanno (1993) and Lee et al. (2004) reported an $\sim 15 \%$ increase in shear strength due to the transverse beam. However, according to the Kanno equation, the increase in connection shear strength is $\sim 10.7 \%$, which is $29 \%$ lower than the test results shown in Table 3 (Lee 2005). Thus, the Kanno equation underestimates the transverse beam mobilization coefficient $\left(C_{t}\right)$. We modified $C_{t}$ using the Kanno equation and test results, as given below:

$$
C_{t}=\left(\frac{1}{2.0}\right) \cdot\left(\frac{d}{b-b_{i}}\right)
$$

where $C_{t}$ is the mobilization coefficient (including the transverse beam effect), $b$ is the connection width, $b_{i}$ is effective internal connection width, and $d$ is the beam height. In this equation, a constant value of $1 / 2.5$ used within the Kanno equation (as shown in Table 1) was replaced by $1 / 2.0$. This results in a $25 \%$ larger $C_{t}$ value than calculated by the Kanno equation. However, we do note that Eq. (2) is based on limited test results, which are later verified using the test results discussed in Sect. 4.

\subsection{Effect of Cover Plates}

The effect of cover plates on connection shear strength is ignored in both ASCE and Kanno equations. However, Lee et al. (2004) showed that the confining force exerted by the cover plate is significant, and that the cover plate should be considered when evaluating shear strength. The shear force exerted by the cover plate can be calculated as

$$
V_{c p}=2 \cdot \alpha \cdot \frac{F_{y c}}{\sqrt{3}} \cdot t_{c}
$$

where $\alpha$ is the strength coefficient, $t_{c}$ the cover plate thickness, and $F_{y c}$ is the cover plate yield stress. Comparisons between shear strength calculations (including the cover plate effect) and test results are shown in Table 4 (Lee

\begin{tabular}{|c|c|c|c|c|c|}
\hline \multirow[t]{2}{*}{ Specimen } & Test & \multicolumn{2}{|c|}{ Kanno equation } & \multicolumn{2}{|c|}{ Proposed equation } \\
\hline & Strength increment $(\%)$ & $C_{w t}$ & Strength increment $(\%$ & $C_{w t}$ & Strength increment $(\%)$ \\
\hline JL0-1 & \multirow[t]{2}{*}{21.8} & 0.21 & \multirow[t]{2}{*}{47} & 0.21 & \multirow[t]{2}{*}{23} \\
\hline JL0-2 & & 1 & & 0.56 & \\
\hline STI-1 & \multirow[t]{2}{*}{15.2} & 0.21 & \multirow[t]{2}{*}{53} & 0.21 & \multirow[t]{2}{*}{22} \\
\hline STI-2 & & 1 & & 0.56 & \\
\hline
\end{tabular}
2005); our proposed equation accurately predicts the

Table 2 Increases in shear strength due to the E-FBP.

$E-F B P$ extended face bearing plates.

Table 3 Increases in shear strength due to transverse beam.

\begin{tabular}{c|c|c|c|c|c}
\hline \multirow{2}{*}{ Specimen } & Test & \multicolumn{2}{|c|}{ Kanno equation } & \multicolumn{2}{c}{ Proposed equation } \\
\cline { 2 - 6 } & Strength increment (\%) & $C_{t}$ & Strength increment (\%) & $C_{t}$ & Strength increment (\%) \\
\hline \hline \multirow{2}{*}{ SNI-1 } & 14.8 & 0.21 & 10.7 & 0.21 & \multirow{2}{*}{0.64} \\
\cline { 3 - 6 } & & 0.51 & & 0.64 \\
\cline { 3 - 6 }
\end{tabular}


Table 4 Increases in shear strength due to the cover plate.

\begin{tabular}{c|c|c|c}
\hline Specimen & $\begin{array}{c}\text { Strength } \\
\text { increment (test) }\end{array}$ & $\begin{array}{c}\text { Strength } \\
\text { increment } \\
\text { (Kanno } \\
\text { equation) }\end{array}$ & $\begin{array}{c}\text { Strength } \\
\text { increment } \\
\text { (proposed } \\
\text { equation) }\end{array}$ \\
\hline \hline LCS-1 & $26.2 \%$ & $4.98 \%$ & $27.53 \%$ \\
\cline { 1 - 1 } LCC-1 & & & \\
\hline
\end{tabular}

increase in shear strength upon addition of a cover plate. In Table 4, LCS-1 and LCC-1 specimens have the same dimensions (except for the cover plate).

\subsection{Proposed Shear Strength Equation}

We previously discussed the effects of a shear key, transverse beams, and cover plates on shear strength. Based on these results, we suggest the following equation for calculating the shear strength of connections in RCS composite systems:

$$
V_{b}=\frac{\left(V_{s} \cdot d_{f}+0.75 V_{n} \cdot d_{w}+V_{n}^{\prime} \cdot d+V_{c p} \cdot d\right)}{\left(\frac{L_{c}}{L_{d}}\left(L_{c}-d_{j}\right)\right)}
$$

(1) Determination of effective width:

- Effective internal element width:

$b_{i}=\max \left(b_{p}, b_{f}\right)$

- Effective external element width:

$$
\begin{aligned}
& b_{0}=C\left(b_{m}-b_{i}\right)<2 d_{0} \\
& b_{m}=\frac{\left(b_{f}+b\right)}{2}<b_{f}+h<1.75 b_{f} \\
& C=\max \left(C_{w t}, C_{t}\right) \\
& C_{w t}=\left(\frac{x}{h}\right) \cdot\left(0.3+0.7 \frac{y}{b}\right)
\end{aligned}
$$

In the above equations, $x=0.7 h$ and $y=0$ without a shear key, $x=h$ and $y=$ the width of the shear key when it is present. $b$ is the connection width.

$$
C_{t}=\left(\frac{1}{2.0}\right) \cdot\left(\frac{d}{b-b_{i}}\right)
$$

(2) Steel beam web shear strength:

$$
V_{s}=\frac{1}{\sqrt{3}} \cdot F_{y w} \cdot t_{w} \cdot j h
$$

(3) Internal concrete shear strength:

$$
V_{n}=1.65 \cdot \sqrt{f_{c k}} \cdot b_{p} \cdot h
$$

(4) External concrete shear strength:

$$
\begin{aligned}
& V_{n}^{\prime}=V_{c}+V_{s} \leq 1.65 \sqrt{f_{c k}} b_{o} h \\
& V_{c}=1.05 \cdot \sqrt{f_{c k}} \cdot b_{o} \cdot h \\
& V_{s}=\frac{A_{s h} \cdot F_{y s h}}{S_{h}} \cdot 0.9 h
\end{aligned}
$$

(5) The cover plate shear strength can be calculated as

$$
V_{c p}=2 \cdot \alpha \cdot \frac{F_{y c}}{\sqrt{3}} \cdot t_{c}
$$

Statistical evaluation was conducted to verify the proposed equations, as described below.

\section{Statistically Evaluating Shear Strength Equations}

\subsection{Comparing Results from Shear Strength Equations with Test Results}

To verify the proposed equations, results from our proposed equation, as well as other shear strength equations, were compared with that of test results. A total of 49 shear failure RCS composite system connection test specimens were selected from previous studies (Dierlein 1988; Sheikh and Deierlein 1989; Kanno 1993; Kei et al. 1990, 1991; Lee et al. 2004; Choi et al. 2003). Test specimens were categorized into four types, depending on connection details: Group A, no shear keys or transverse beams; Group B, shear keys but no transverse beams; Group C, transverse beams but no shear key; and Group D, has both a shear key and a transverse beam. All connection details (according to group) are shown in Fig. 4.

We next used these test specimens to compare shear strength values derived from all equations with test results, as shown in Fig. 5. In Fig. 5, the $x$-axis represents calculated values (CalQc) and the $y$-axis the test results (ExpQc). These comparisons show that the ASCE equation underestimates the connection's shear strength, with a larger discrepancy between test results for specimens with transverse beams. This is because the ASCE equation does not contain a parameter related to the presence of a transverse beam in the connection. Estimates of shear strength from the Kanno equation more closely agree with the test results compared with those of the ASCE. However, test results with a welded 


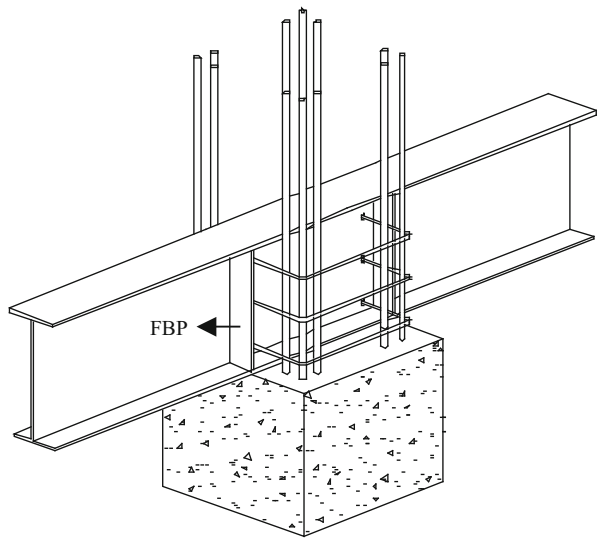

(a)

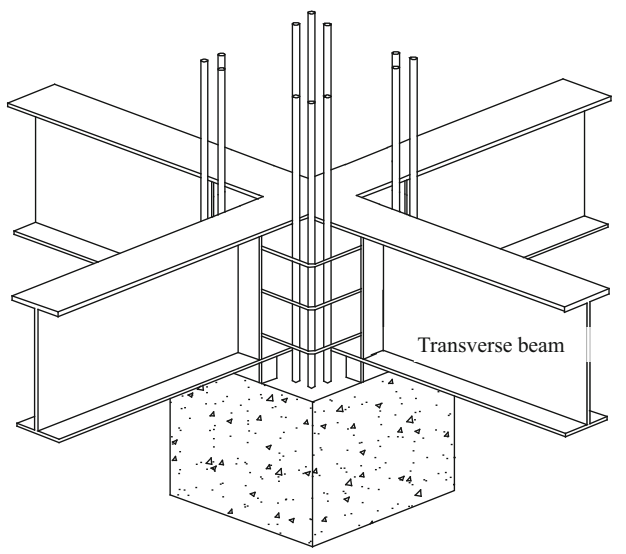

(c)

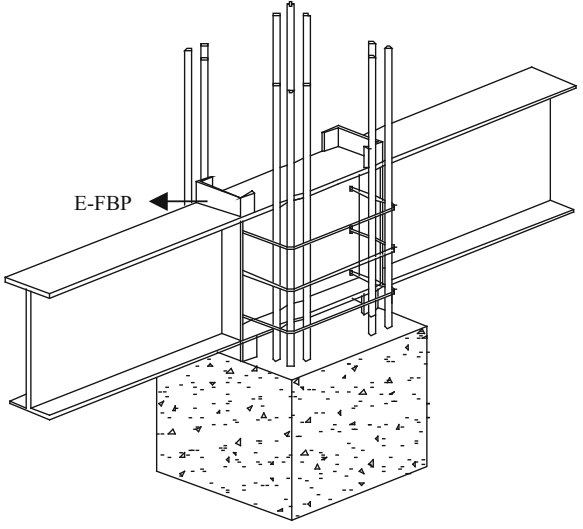

(b)

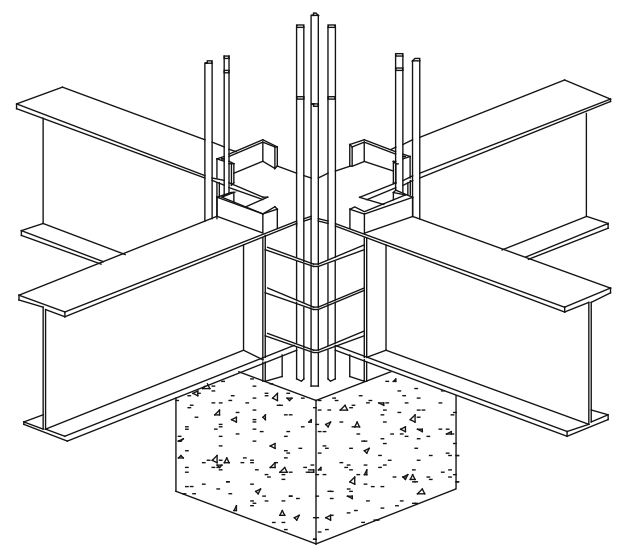

(d)

Fig. 4 Connection details for each group: a Group A, b Group B, c Group C, and d Group D.

cover plate show a large discrepancy for the Kanno and M-Kanno equation, even if the simplified calculation method is used. Results from the Architectural Institute of JapanStandard for Structural Calculation of Steel Reinforced Concrete Structures (AIJ-SRC) produced average accuracy results of $\sim 86 \%$, with a standard deviation of 0.37 (the largest value among all equations). M-AIJ-SRC resulted in a standard deviation of 0.27 , which is greater than that from ASCE and Kanno equations; this is because AIJ-SRC and M-AIJ-SRC do not consider shear keys, such as an E-FBP or band plate.

\subsection{Sample size}

The sample size within the statistical analysis must be defined to ensure reliability and range. In conventional statistical analyses, the sample size is defined to guarantee target reliability levels and range. However, sampling size was fixed in this study; thus, reliability level and range were calculated to validate sampling size.

Sampling size (as a ratio) can be expressed as

$$
n=\frac{Z_{\alpha / 2}^{2} \cdot \alpha^{2}}{e^{2}}
$$

where $\alpha=0.3$ (population standard deviation) and $e= \pm 0.1$ (permitted limit of error).

We found that between 35 and 59 samples are needed to guarantee reliability levels of 95 and $99 \%$, respectively. Thus, 49 samples were used in this study to satisfy a reliability level of $95 \%$.

\subsection{Statistical Analysis Results}

Statistical analysis was conducted for the 49 test results to investigate all shear strength equations (as shown in Table 5). The ratios of estimated shear strength from the ASCE equation to test results ranged from 0.47 to 1.16 ; this equation underestimated shear strength by $27 \%$ compared with test results. Alternatively, Kanno equations showed only a $6 \%$ discrepancy compared with test results. Our proposed equation showed the lowest value for standard deviation (0.11) and best fit to test results with regard to shear strength. The averaged standard error represents the averaged error obtained using the standard deviation and reliability coefficients. Our proposed equation showed the smallest averaged standard error, as well as the smallest standard deviation. Thus, our proposed equation accurately 


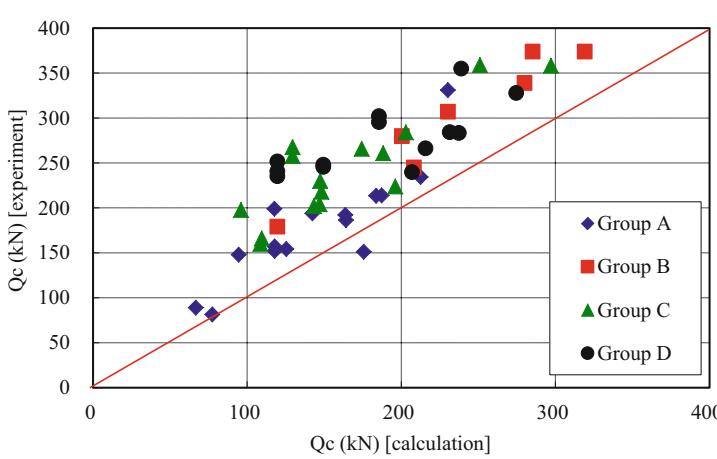

(a)

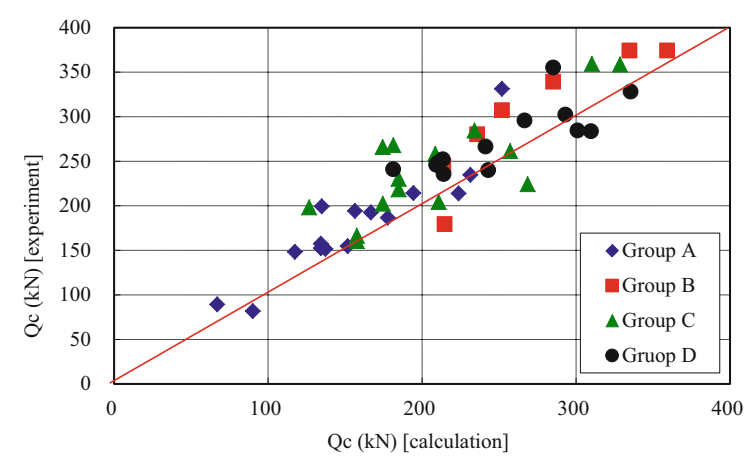

(c)

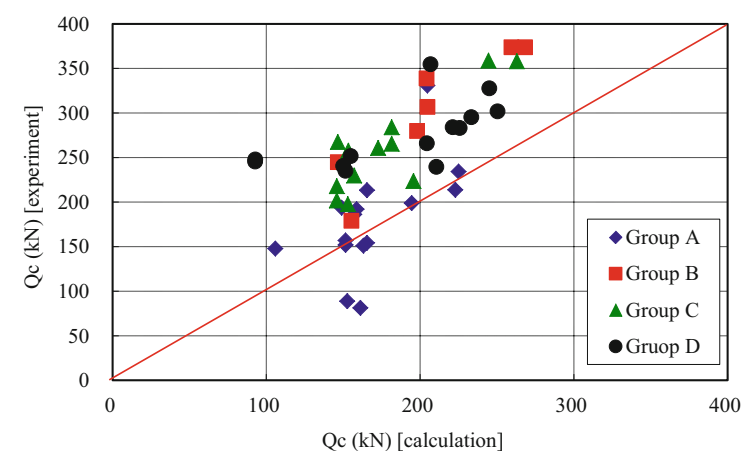

(e)

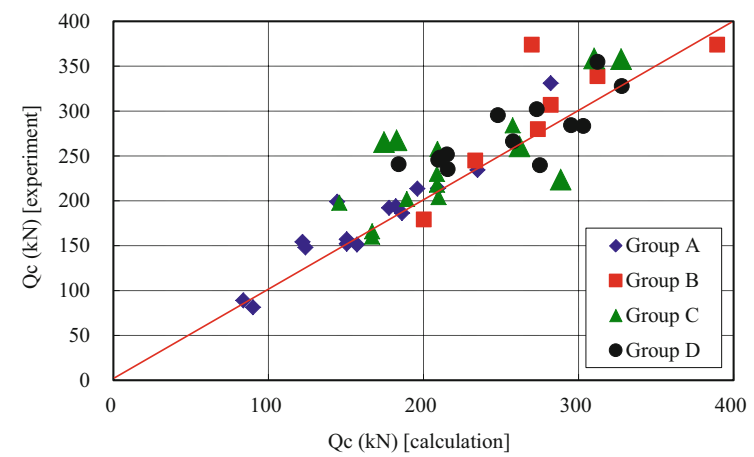

(b)

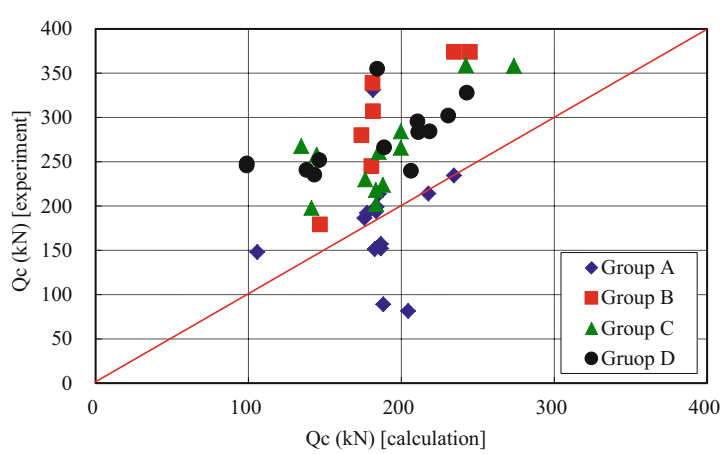

(d)

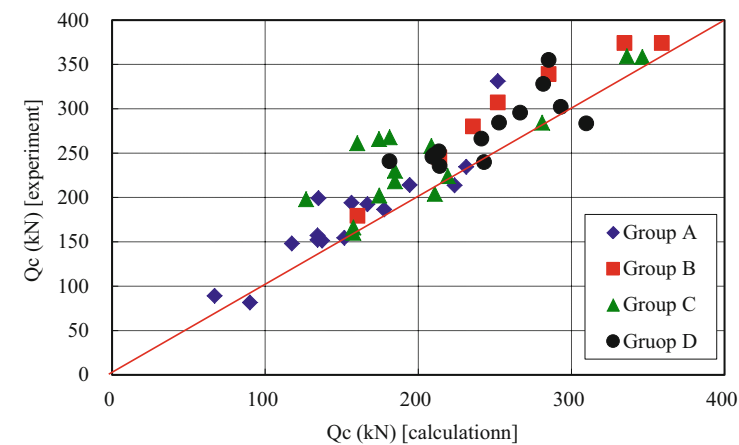

(f)

Fig. 5 Comparing equations with test results: a American Society of Civil Engineers (ASCE) equation, b Kanno equation, $\mathbf{c}$ MKanno equation, $\mathbf{d}$ Architectural Institute of Japan (AIJ) equation, e M-AIJ equation, and $\mathbf{f}$ our proposed equation.

Table 5 Statistical analysis results.

\begin{tabular}{c|c|c|c|c|c|c}
\hline $\begin{array}{c}\text { Statistical } \\
\text { parameter }\end{array}$ & ASCE & Kanno & M-Kanno & AIJ & M-AIJ & Proposed \\
\hline \hline Min. & 0.47 & 0.68 & 0.64 & 0.40 & 0.37 & 0.61 \\
\hline Max. & 1.16 & 1.29 & 1.20 & 2.51 & 1.98 & 0.81 \\
\hline Mean & 0.73 & 0.94 & 0.90 & 0.86 & 0.04 & 0.88 \\
\hline Std. error of mean & 0.02 & 0.02 & 0.02 & 0.05 & 0.27 & 0.11 \\
\hline Standard deviation & 0.14 & 0.12 & 0.12 & 0.37 & 0.14 & 0.07 \\
\hline Variance & 0.02 & 0.01 & 0.01 & 2.61 & 2.42 & 0.32 \\
\hline Skewness & 0.20 & 0.24 & 0.39 & 9.34 & 9.04 & 0.26 \\
\hline Kurtosis & 0.68 & 0.90 & 0.35 & &
\end{tabular}


predicts the shear strength of connections in RCS composite systems.

Skewness represents the skewed angle and direction of the data distribution, and kurtosis represents the sharpness of the data distribution; the skewness and kurtosis for each equation is shown in Table 5. The skewness was greater than zero for all equations, such that most estimated and test result values were larger than 1, indicating that the equations provide a safe estimation of shear strength. Skewness for the ASCE and M-AIJ equations

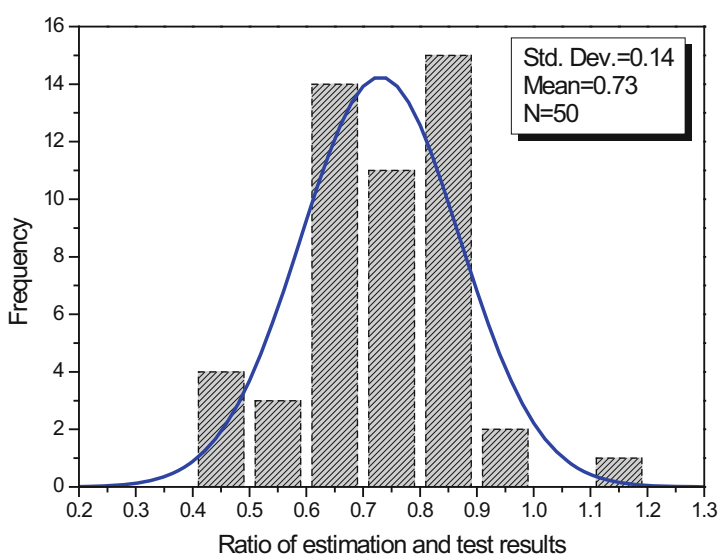

(a)

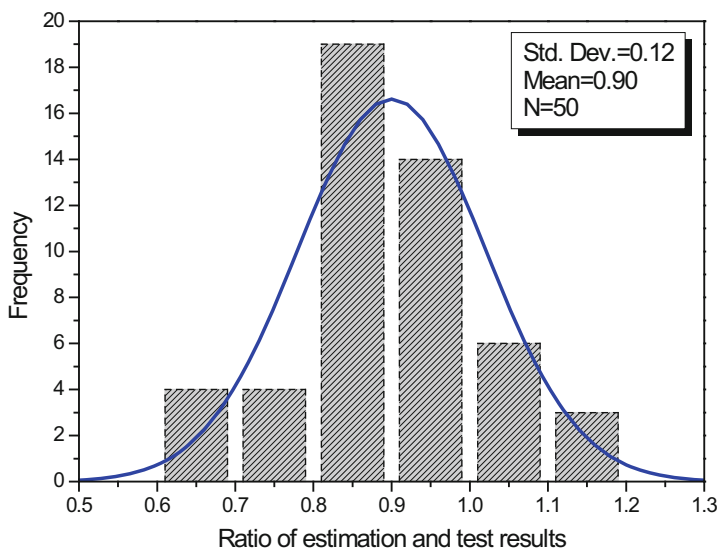

(d)

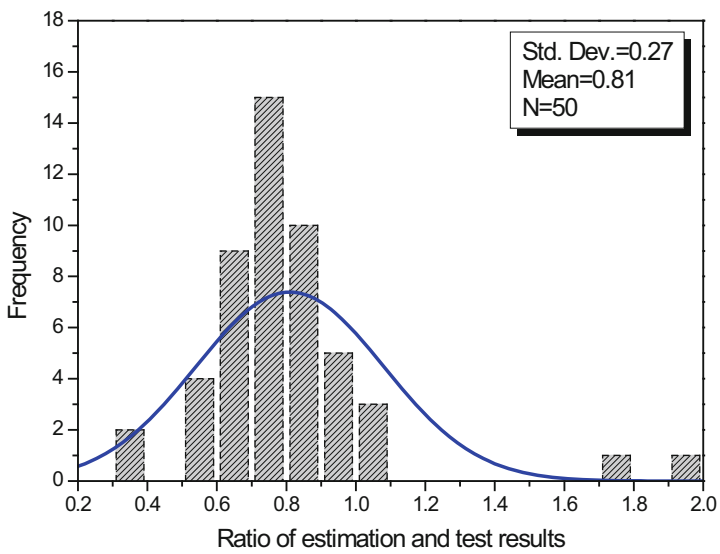

(e) was greater than that for the other equations, indicating that these equations underestimate shear strength to a greater extent than the others. The kurtosis of all equations was also larger than 0 . This means that the data distribution is sharper than standard normal distributions, where data are concentrated around a specific value. The kurtosis value for the Kanno equation was somewhat large; however, this was not a significant problem as data were concentrated around the average value, as shown in the histogram in Fig. 6. On the other hand, data were

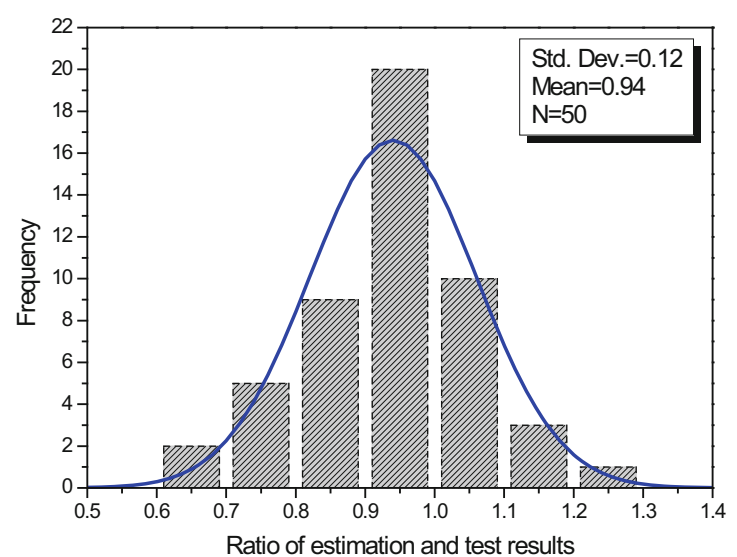

(b)

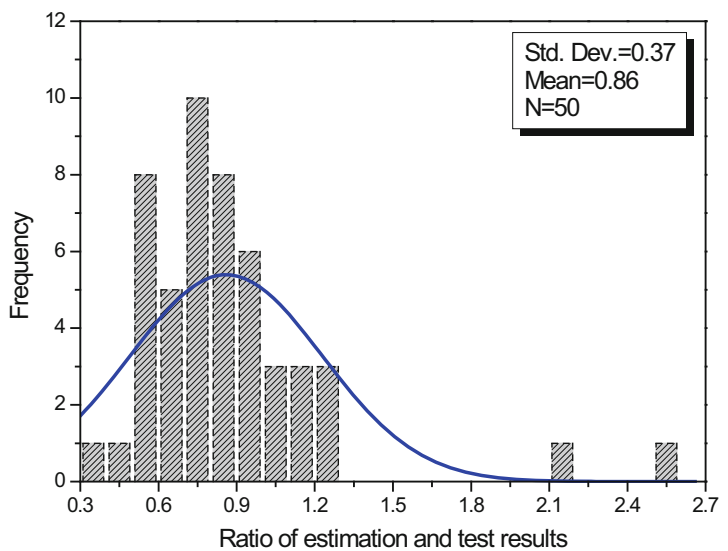

(d)

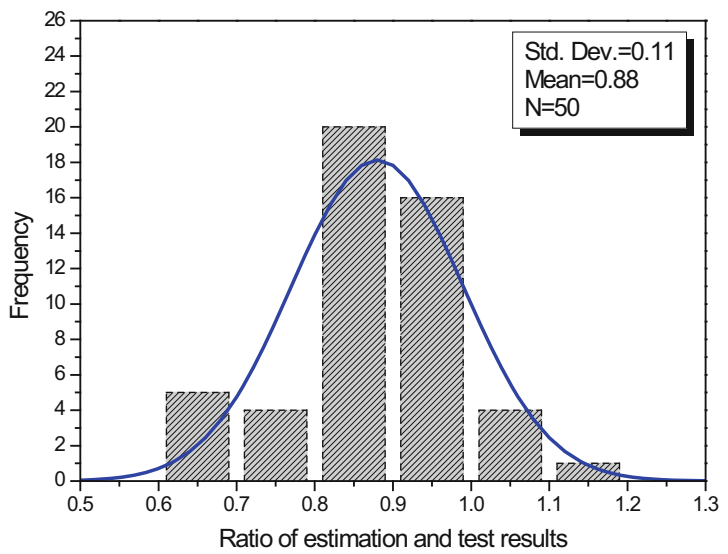

(f)

Fig. 6 Histograms and normal distribution curves: a ASCE equation, b Kanno equation, c M-Kanno equation, d AIJ equation, e MAlJ equation, and $\mathbf{f}$ our proposed equation. 
concentrated in several specific sections with an irregular distribution for the AIJ and M-AIJ equations, making it difficult for these equations to satisfy a normal distribution.

Frequency histograms and normal distributions are plotted in Fig. 6; in this figure, the $x$-axis represents the estimation/ test ratio, and the $y$-axis the frequency. The histograms were in good agreement with normal distributions for the Kanno, M-Kanno, and our proposed equation, while the distribution of data from AIJ and M-AIJ equations was far from normal. A $0.63-0.75$ shear strength range was the most popular for the ASCE equation. Thus, our proposed equation provided the most accurate prediction of shear strength, given that it had the smallest standard deviation, averaged standard error, and a normal data distribution.

\subsection{Factor Analysis}

We next conducted factor analysis to reduce parameters to those with the greatest effect on connection shear strength. Five major factors were selected from the factor analysis, and each factor (Factor 1-5) was matched with test and shear strength equations, as shown in Table 6. Table 6 also shows the degree of correlation between each factor and connection group (Fig. 4). For example, Group A showed a high degree of correlation between the test results and Factor 4 (0.96). Groups $\mathrm{B}, \mathrm{C}$, and $\mathrm{D}$ also showed a high degree of correlation with

Table 6 Factor analysis results.

\begin{tabular}{|c|c|c|c|c|c|c|}
\hline \multirow[t]{2}{*}{ Test or equations } & \multirow[t]{2}{*}{ Group } & \multicolumn{5}{|c|}{ Factor } \\
\hline & & 1 & 2 & 3 & 4 & 5 \\
\hline \multirow[t]{4}{*}{ Test } & A & 0.17 & 0.00 & 0.20 & 0.96 & -0.05 \\
\hline & $\mathrm{B}$ & 0.28 & 0.93 & -0.04 & 0.21 & 0.03 \\
\hline & $\mathrm{C}$ & -0.24 & -0.11 & 0.92 & -0.21 & 0.14 \\
\hline & $\mathrm{D}$ & 0.95 & 0.16 & -0.21 & -0.14 & 0.11 \\
\hline \multirow[t]{4}{*}{ ASCE } & A & -0.26 & 0.26 & 0.63 & 0.61 & -0.21 \\
\hline & B & 0.25 & 0.87 & -0.17 & 0.38 & 0.04 \\
\hline & $\mathrm{C}$ & 0.00 & -0.17 & 0.95 & 0.26 & 0.01 \\
\hline & $\mathrm{D}$ & 0.86 & 0.17 & -0.02 & -0.02 & 0.48 \\
\hline \multirow[t]{4}{*}{ Kanno } & $\mathrm{A}$ & -0.09 & -0.03 & 0.59 & 0.78 & 0.17 \\
\hline & $\mathrm{B}$ & -0.06 & 0.76 & -0.20 & 0.55 & -0.22 \\
\hline & $\mathrm{C}$ & 0.16 & -0.37 & 0.85 & 0.33 & 0.04 \\
\hline & $\mathrm{D}$ & 0.99 & -0.04 & 0.12 & -0.07 & -0.01 \\
\hline \multirow[t]{4}{*}{ M-Kanno } & A & -0.20 & 0.37 & 0.21 & 0.88 & 0.11 \\
\hline & B & 0.15 & 0.90 & -0.38 & 0.02 & -0.13 \\
\hline & $\mathrm{C}$ & 0.12 & -0.39 & 0.88 & 0.23 & 0.07 \\
\hline & $\mathrm{D}$ & 0.99 & 0.04 & 0.07 & -0.08 & 0.03 \\
\hline \multirow[t]{4}{*}{ AIJ } & $\mathrm{A}$ & 0.29 & 0.36 & -0.20 & -0.75 & 0.41 \\
\hline & $\mathrm{B}$ & 0.06 & 0.92 & -0.28 & -0.09 & 0.22 \\
\hline & $\mathrm{C}$ & -0.26 & -0.30 & 0.73 & 0.41 & 0.38 \\
\hline & $\mathrm{D}$ & 0.86 & 0.31 & -0.16 & -0.15 & -0.32 \\
\hline \multirow[t]{4}{*}{ M-AIJ } & A & 0.74 & 0.23 & -0.08 & 0.48 & -0.40 \\
\hline & B & 0.13 & 0.96 & -0.12 & -0.13 & -0.07 \\
\hline & $\mathrm{C}$ & -0.12 & -0.16 & 0.88 & 0.42 & -0.01 \\
\hline & $\mathrm{D}$ & 0.83 & 0.35 & -0.18 & -0.17 & -0.35 \\
\hline \multirow[t]{4}{*}{ Proposed } & $\mathrm{A}$ & -0.20 & 0.37 & 0.21 & 0.88 & 0.11 \\
\hline & $\mathrm{B}$ & 0.24 & 0.95 & -0.19 & 0.09 & 0.00 \\
\hline & $\mathrm{C}$ & 0.07 & -0.18 & 0.92 & 0.03 & -0.34 \\
\hline & $\mathrm{D}$ & 0.99 & 0.14 & 0.01 & -0.04 & 0.08 \\
\hline
\end{tabular}

Bold values in the table show the highest degree of correlation for each factor with connection group depicted in Fig. 4. 
Factors 2, 3, and 1 (respectively), as shown in Table 6. Factor 5 had a low degree of correlation with Groups A-D (the largest degree of correlation was 0.41 ), such that only Factors 1-4 were considered in this study. For Factors 1-4, each showed a strong relationship with a specific connection group:

(1) Factor 1 was related to E-FBP and transverse beams (Group D),

(2) Factor 2 was related to E-FBP and no transverse beam (Group B),

(3) Factor 3 was related to transverse beam and no E-FBP (Group C),

(4) Factor 4 was related to no E-FBP or transverse beams (Group A).

Factors 1, 2, 3, and 4 are highly related to Groups D, B, C, and A, respectively. However, Group A is most related to Factor 3 for the ASCE equation. Thus, the ASCE equation may not be appropriate to predict the shear strength of Group
A-type materials. Additionally, Group A showed ambiguous correlation with factors for AIJ and M-AIJ equations; thus, AIJ and M-AIJ equations should be applied carefully to Group A-type RCS connections.

\subsection{Correlation Analysis}

Correlation analysis between test results and shear strength equations was conducted; the results are shown in Table 7. ASCE, AIJ, and M-AIJ equations all exhibited low correlation values $(<0.7)$ for Group $\mathrm{A}$, in which no shear key or transverse beams were installed. Correlation with Group B was weaker than the others for the Kanno equation. Additionally, Group C (which does not contain E-FBP, but does contain transverse beams) showed weak correlation with all equations, even if the ASCE equation showed the strongest correlation with Group C. This implies that parameters related to E-FBP are not well represented in shear strength equations. Our proposed equation showed the strongest correlation for

Table 7 Correlation coefficients.

\begin{tabular}{|c|c|c|c|c|c|}
\hline \multirow[t]{2}{*}{ Equations } & \multirow[t]{2}{*}{ Group } & \multicolumn{4}{|c|}{ Test } \\
\hline & & $\mathrm{A}$ & $\mathrm{B}$ & $\mathrm{C}$ & $\mathrm{D}$ \\
\hline \multirow[t]{4}{*}{ ASCE } & A & 0.65 & 0.27 & 0.41 & -0.45 \\
\hline & B & 0.35 & 0.97 & -0.41 & 0.36 \\
\hline & $\mathrm{C}$ & 0.44 & -0.14 & 0.84 & -0.26 \\
\hline & $\mathrm{D}$ & 0.11 & 3416.00 & -0.16 & 0.91 \\
\hline \multirow[t]{4}{*}{ Kanno } & A & 0.84 & 0.10 & 0.41 & -0.30 \\
\hline & $\mathrm{B}$ & 0.50 & 0.81 & -0.37 & 0.02 \\
\hline & $\mathrm{C}$ & 0.52 & -0.26 & 0.73 & -0.12 \\
\hline & $\mathrm{D}$ & 0.12 & 0.22 & -0.11 & 0.91 \\
\hline \multirow[t]{4}{*}{ M-Kanno } & $\mathrm{A}$ & 0.84 & 0.47 & 0.03 & -0.28 \\
\hline & B & -0.02 & 0.90 & -0.50 & 0.35 \\
\hline & $\mathrm{C}$ & 0.42 & -0.31 & 0.79 & -0.16 \\
\hline & $\mathrm{D}$ & 0.10 & 0.30 & -0.16 & 0.94 \\
\hline \multirow[t]{4}{*}{ AIJ } & $\mathrm{A}$ & 0.74 & 0.28 & -0.09 & 0.52 \\
\hline & B & -0.16 & 0.87 & -0.35 & 0.29 \\
\hline & $\mathrm{C}$ & 0.48 & -0.28 & 0.73 & -0.46 \\
\hline & $\mathrm{D}$ & -0.03 & 0.50 & -0.41 & 0.88 \\
\hline \multirow[t]{4}{*}{ M-AIJ } & $\mathrm{A}$ & 0.59 & 0.52 & -0.43 & 0.65 \\
\hline & $\mathrm{B}$ & -0.11 & 0.91 & -0.21 & 0.32 \\
\hline & $\mathrm{C}$ & 0.54 & -1318.00 & 0.74 & -0.39 \\
\hline & $\mathrm{D}$ & -0.06 & 0.52 & -0.42 & 0.86 \\
\hline \multirow[t]{4}{*}{ Proposed } & $\mathrm{A}$ & 0.84 & 0.47 & 0.03 & -0.28 \\
\hline & B & 0.09 & 0.98 & -0.35 & 0.40 \\
\hline & $\mathrm{C}$ & 0.25 & -0.18 & 0.80 & -0.20 \\
\hline & $\mathrm{D}$ & 0.12 & 0.41 & -0.22 & 0.97 \\
\hline
\end{tabular}

Bold values in the table show the highest degree of correlation between test results and shear strength equations with respect to connection group depicted in Fig. 4. 
Group D; thus, our equation accurately encompassed the effects of E-FBP and transverse beams in shear strength calculations. Taken together, these results demonstrate that our proposed equation best predicted the shear strength of RCS connections, as compared across all equations.

\section{Conclusions}

In this paper, we introduced an equation for calculating shear strength for connections in RCS composite systems, with verification by statistical analysis. The major findings of this paper are given below:

(1) The effect of E-FBP and transverse beams on the shear strength of connections in RCS composite systems can be accurately evaluated by mobilization coefficients representing the shear key and transverse beams.

(2) The proposed equation considers the confining effects of adding a cover plate and, in doing so, provides a good estimation of the shear strength due to this cover plate.

(3) Statistical analysis showed that the proposed equation is the most accurate, compared with previously investigated equations. This analysis also categorized RCS composite system connections into four groups, based on factor analysis results.

(4) Correlation analysis showed that our proposed equation correlates well with connection details from the RCS composite system.

\section{Acknowledgements}

This work was supported by a 2016 Chungwoon University Foundation Grant and a Grant from the Technology Advancement Research Program (15CTAP-C097490-01), funded by the Korean Ministry of Land, Infrastructure, and Transport Affairs.

\section{Open Access}

This article is distributed under the terms of the Creative Commons Attribution 4.0 International License (http://creativecommons.org/licenses/by/4.0/), which permits unrestricted use, distribution, and reproduction in any medium, provided you give appropriate credit to the original author(s) and the source, provide a link to the Creative Commons license, and indicate if changes were made.

\section{References}

Architectural Institute of Japan (1975 and 1987). Standard for Structural Calculation of Steel Reinforced Concrete Structures, AIJ Standard.
ASCE. (1993). Task committee on design criteria for composite structures in steel and concrete. Guidelines for design of joints between steel beams and reinforced concrete columns. ASCE Journal, 127(1), 2330-2357.

Choi, K., Yoo, Y., \& Lee, L. (2003). Shear behavior of beamcolumn joints composed of reinforced concrete columns and steel beams. Journal of the Architectural institute of Korea, 19(8), 19-26 (in Korean).

Dierlein, G. G. (1988). Design of Moment Connections for Composite Framed Structures. Ph.D. Dissertation, Department of Civil Engineering, University of Texas at Austin.

Kanno, R. (1993). Strength, deformation, and seismic resistance of joints between steel beams and reinforced concrete columns (Vol. 1 and 2). Ithaca, NY: Cornell University.

Kanno, R. (2002). Evaluation of existing strength models for RCS joints and consideration toward improved modeling: A study on strength evaluation of RCS joints part 1 . Journal of Structural and Construction Engineering, 553, 135.

Kei, T. et al. (1990). An experimental study on RC columnssteel beams joints, Part $1 \& 2$. Abstracts at Annual Meeting of AIJ, pp. 1183-1186 (in Japanese).

Kei, T. et al. (1991). An experimental study on RC columnssteel beams joints, Part $3 \& 4$. Abstracts at Annual Meeting of AIJ, pp. 1623-1626 (in Japanese).

Kim, S. S., \& Choi, K. H. (2006). Load transfer mechanism of a hybrid beam-column connection system with structural tees. International Journal of Concrete Structures and Materials, 18(3E), 199-205.

Kim, J. K., \& Choi, H. H. (2015). Monotonic loading tests of $\mathrm{RC}$ beam-column subassemblage strengthened to prevent progressive collapse. International Journal of Concrete Structures and Materials, 9(4), 401-413.

LaFave, J. M., \& Kim, J. H. (2011). Joint shear behavior prediction for RC beam-column connections. International Journal of Concrete Structures and Materials, 5(1), 57-64.

Lee, E.-J. (2005). Shear Behavior of Hybrid Connection Consisted of Reinforced Concrete Column and Steel Beam. Ph.D. thesis, Hanyang University, Seoul, South Korea (in Korean).

Lee, E.-J., Moon, J.-H., \& Lee, L.-H. (2004). An experimental study on the behavior of reinforced concrete column and steel beam (RCS) joints with cover plate type. Journal of the Architectural Institute of Korea, 20(7), 37-44 (in Korean)

Lee, E.-J., Moon, J.-H., \& Lee, L.-H. (2005). Shear behavior of beam-column joints composed of reinforced concrete columns and steel beams. Journal of the Architectural Institute of Korea, 21(3), 61-68 (in Korean).

Lim, K. M., Shin, H. O., Kim, D. J., Yoon, Y. S., \& Lee, J. H. (2016). Numerical assessment of reinforcing details in beam-column joints on blast resistance. International Journal of Concrete Structures and Materials, 10 (3 Supplement), 87-96.

Mikame, A. (1990). Mixed structural systems of precast concrete columns and steel beams, Part I, II \& III. Abstracts at Annual Meeting of AIJ, pp. 1643-1646 (in Japanese). 
Mikame, A. (1992). Mixed structural systems of precast concrete columns and steel beams, Part VI \& VII. Abstracts at Annual Meeting of AIJ, pp. 1899-1902 (in Japanese).

Nishimura, Y. (1986). Stress transfer mechanism of exterior connection consisting of steel beam and steel reinforced concrete (SRC) column. Journal of Structural Engineering, $32 B, 135-146$.
Sheikh, T. M., \& Deierlein, G. G. (1989). Beam-column moment connections for composite frames: Part 1. Journal of Structural Engineering ASCE, 115(11), 2858-2896.

Yang, K. H., Ashour, A. F., \& Song, J. K. (2007). Shear capacity of reinforced concrete beams using neural network. International Journal of Concrete Structures and Materials, 1(1), 63-73. 